\title{
Depressão e sintomas depressivos: confusão conceitual
}

\author{
Depression and depressive symptoms: conceptual confusion
}

Lucas Spanemberg'

Prezado editor,

A respeito do artigo intitulado "Prevalência de depressão entre homens adultos em situação de rua em Belo Horizonte" ${ }^{\prime \prime}$, cabem algumas considerações.

Em primeiro lugar, os estudos dirigidos à saúde mental de populações vulneráveis são sempre bem-vindos, uma vez que instrumentam os agentes políticos e gestores de saúde para as necessárias intervenções nessas populações. Ainda que questões sociais possam ser determinantes para a condição dessas pessoas, é evidente que muitas delas são portadoras de doenças mentais graves e passam por sofrimento psíquico significativo, cabendo também ao Estado a construção de políticas públicas pertinentes à problemática. Nesse sentido, estudos que avaliem diagnósticos e intensidade de sintomas nessas populações são necessários e pertinentes. Contudo, cabem aqui alguns comentários conceituais sobre o estudo.

O título do trabalho utiliza o termo "prevalência de depressão", definindo o diagnóstico de depressão com um ponto de corte de 12 pontos no Inventário de Depressão de Beck (BDI). Como o próprio artigo explica, esse instrumento foi desenvolvido para avaliar a intensidade dos sintomas depressivos, não sendo um instrumento diagnóstico, ainda que um ponto de corte possa ser utilizado como screening de quadros depressivos. Contudo, durante grande parte do artigo, o termo "depressão" ou "quadro depressivo" foi utilizado como diagnóstico categórico, ainda que nenhuma escala diagnóstica tenha sido aplicada, podendo induzir o leitor ao erro. Ainda que essa limitação tenha sido considerada brevemente, todas as tabelas levam a denominação "depressão", e não "sintomas depressivos", da mesma forma que o título. Esse é um grave erro conceitual comum em nosso meio² e pode acarretar superestimação diagnóstica da depressão. Além disso, alguns dos sintomas depressivos avaliados pela BDI podem decorrer de outras patologias ou ser mais bem explicados pelas próprias condições desses indivíduos. O título e as tabelas estão, dessa forma, com termos equivocados e confundem o leitor.

Por fim, o artigo contribui para a discussão da problemática em relação ao sofrimento mental de moradores de rua, mas peca na descrição de conceitos. Penso que os autores devem ser estimulados a seguirem com estudos nessa população, mas com maior cuidado no uso dos termos. A literatura científica deve primar pelo rigor nos conceitos, uso adequado dos instrumentos e clareza das informações, ou corremos o risco de equívocos e extrapolações indevidas, num universo científico já inundado de estatísticas controversas.

\section{REFERÊNCIAS}

1. Botti NCL, Castro CGd, Silva MF, et al. Prevalência de depressão entre homens adultos em situação de rua em Belo Horizonte. J Bras Psiquiatr. 2010;59:10-6.

2. Spanemberg L. Depressão pós-parto: considerações terminológicas. Rev Psiquiatr Rio Gd Sul. 2008;30:85-6.

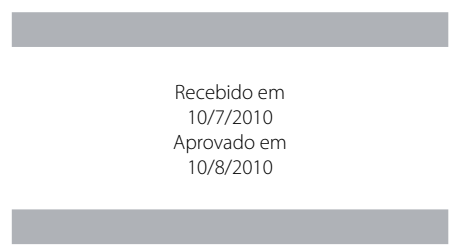

1 Pontifícia Universidade Católica do Rio Grande do Sul (PUC-RS), Hospital São Lucas, Unidade de Internação Psiquiátrica; Universidade Federal do Rio Grande do Sul (UFRGS), Hospital de Clínicas de Porto Alegre, Programa de Pós-Graduação em Psiquiatria.

Endereço para correspondência: Lucas Spanemberg

Hospital São Lucas, PUCRS, Unidade de Internação, Psiquiátrica - $6^{0}$ andar sul

Av. Ipiranga, 6.690 - 90160-090 - Porto Alegre, RS

Telefone: (51) 3320-3041

E-mail: Ispanemberg@yahoo.com.br 